\title{
Social Appearance Anxiety in Patients with Acne Vulgaris: A Cross-Sectional Controlled Study
}

\author{
๑ Faruk Kurhan, ๑ Goknur Ozaydin Yavuz* • ๑ Kubra Tatar* \\ Van Yuzuncu Yil University Faculty of Medicine, Department of Psychiatry, Van, Turkey \\ *Yuzuncu Yıl University Faculty of Medicine, Department of Dermatology, Van, Turkey
}

Abstract

\begin{abstract}
Aim: The purpose of our study is to identify the extent to which acne vulgaris patients with facial involvement are affected by this condition which may negatively affect the self-perception of individuals.

Methods: A total of 122 acne vulgaris patients with facial involvement between the ages of 18-65 and 115 healthy controls that were matched in terms of age, gender and educational status have included in the study. Patients and healthy controls were asked to fill in social appearance anxiety scale (SAAS) and hospital anxiety depression scale, and dermatology life quality index and visual analog scales were applied to the patient group. The study was designed as a cross-sectional controlled study which is a type of observational study. The data of this study were collected among those who applied to the dermatology outpatient clinic between 01.03.2020-01.10.2020. The control group was selected from the hospital staff who were healthy and volunteers.
\end{abstract}

Results: Average SAAS scores of the patient, and the control group were 55.20, and 19.70 points, respectively. Thus, the average SAAS score of the patient group was found to be significantly higher than that of the control group $(p<0.01)$.

Conclusion: Acne lesions in acne vulgaris patients that appear on visible skin surfaces cause anxiety in individuals due to their appearance. This condition revealed that those with acne lesions should undergo psychiatric as well as dermatological treatments.

Keywords: Acne vulgaris, anxiety, depression, social appearance anxiety

\section{Introduction}

Acne vulgaris is a chronic inflammatory dermatosis with predilection on the face and upper body, predominantly areas populated with pilosebaceous units. Depending on the clinical severity in patients, it may manifest itself with erythematous papules and pustules, comedones, nodulocystic lesions and scarring (1). Its four main etiopathogenetic factors are increased sebum manufacture, extreme cornification of the pilosebaceous canal, microbial habitats and inflammation (2).

Acne vulgaris is one of the most common dermatoses, and the relationship between acne and psychological factors has been investigated for many years. Existing lesions in acne patients may worsen with emotional stress, and psychological and psychiatric problems may develop in patients with the exacerbation of the lesions (3). In some case series, patients with acne vulgaris accompanied by psychological diseases like anxiety, depression, suicidal thoughts have been reported (4). It is believed that anxiety is a factor that worsens the disease in $74 \%$ of acne patients (5). Some studies have found increased frequency of anxiety in diseases with acne vulgaris, and a direct proportion among the severity of anxiety and the seriousness of acne has been indicated (1).

Undoubtedly, the most can be seen and widest organ of our body is the skin. It significantly affects the physical appearance. To have a healthy skin structure plays an important role in preserving the physical, mental, inner and social welfare of the individual. The face is an important part of your body with regard to human attractiveness to the counter sex (6). As a result, dermatoses, especially on the face, may cause deterioration of physical and mental health, low self-esteem, trouble and disturbances in social interplays (7). Difficulties that social appearance anxiety (SAA) may cause in the lives of patients with acne vulgaris

Address for Correspondence: Faruk Kurhan, Van Yuzuncu Yil University Faculty of Medicine, Department of Psychiatry, Van, Turkey 
can lead to loss of workforce, problems in family and most importantly, in social relationships. In this study, we have researched the effects of acne vulgaris on anxiety levels of patients caused by their social appearance.

\section{Methods}

\section{Study Design and Patient Evaluation}

The required written permissions of the study were obtained from Medical Faculty at Van Yuzuncu Yil University Hospital Ethics Committee and the participants with the decision number 2020/02-10 and date 21/02/2020. Volunteered participants who signed informed consent forms were enrolled in the study

The study was designed as a cross-sectional controlled study which is a type of observational study. The data were collected among those who applied to the dermatology outpatient clinic between 01.03.2020-01.10.2020. The control group was selected from the hospital staff who were healthy and volunteers. A total of 122 acne vulgaris patients with facial involvement between the ages of 1865 and 115 healthy controls that were matched in terms of age, gender, and educational status have included in the study.

Patients and healthy controls were asked to fill in SAA scale (SAAS) (8) and hospital anxiety depression (HAD) (9) scale, and dermatology life quality index (DLQI) (10) and visual analog scales were applied to the patient group.

\section{Statistical Analysis}

Descriptive statistics were used to sum up the demographic and clinical characteristics of the case and control groups. The cruciality of the differences between the two groups was assessed by an independent sample t-test. The Pearson correlation test was adjusted to calculate correlations between variables. Statistical analysis was carried out using the SPSS 22.0 statistical package, and the level of significance have set at $p<0.05$.

\section{Results}

Hundred and twenty-two acne vulgaris patients (46 men, and 76 women) and 115 control subjects (49 men, and 66 women) were included in the study. The mean ages of acne patients, and the control group were $25.844 \pm 6.354$, and $25.80 \pm 5.713$ years, respectively. The age, gender, marital status, educational status, occupational and other sociodemographic data of the groups are given in (Table 1).

According to the consequence of the t-test; any important difference was not observed between acne vulgaris and control groups. With regard to age and gender distribution, but the HAD anxiety subscale, HAD depression subscale and SAAS values were found to be important higher in the patient group relative to the control group $(p<0.05)$ (Table 2$)$.

The difference between the patient and control groups with regard to mean SAAS scores was found to be statistically important. The mean SAAS score of the patient group was found to be rather higher relative to the control group $(p<0.01)$ (Table 2$)$.

The difference between the case and control groups with regard to the mean HAD depression subscale scores was found to be statistically significant. The mean HAD depression subscale scores of the patient group was found to be higher than the control group $(p<0.05)$ (Table 2$)$.

The correlation coefficient between the SAAS scores and the HAD anxiety subscale scores was 0.753 (75.3\%) which indicated the presence of statistically significant

\begin{tabular}{|c|c|c|c|}
\hline & & $\begin{array}{l}\text { Acne vulgaris } \\
\text { group } \\
(n=122)\end{array}$ & $\begin{array}{l}\text { Control goup } \\
(n=115)\end{array}$ \\
\hline Age & (Years) (Mean \pm SD) & $25.844 \pm 6.354$ & $25.80 \pm 5.713$ \\
\hline \multirow{2}{*}{ Gender } & Male [n (\%)] & $46(37.7)$ & $49(42.6)$ \\
\hline & Female [n (\%)] & $76(62.3)$ & $66(57.4)$ \\
\hline \multirow{2}{*}{$\begin{array}{l}\text { Marital } \\
\text { status }\end{array}$} & Married & $63(51.6)$ & $51(44.3)$ \\
\hline & Single & $59(48.4)$ & $64(55.7)$ \\
\hline \multirow{3}{*}{$\begin{array}{l}\text { Educational } \\
\text { status }\end{array}$} & Primary school & $48(39.3)$ & $39(33.9$ \\
\hline & High school & $10(8.2)$ & $10(8.7)$ \\
\hline & University & $64(52.5)$ & $66(57.4)$ \\
\hline \multirow{4}{*}{ Occupation } & Student & $49(40.2)$ & $41(35.7)$ \\
\hline & Unemployed & $10(8.2)$ & $9(7.8)$ \\
\hline & Housewife & $38(31.1)$ & $37(32.2)$ \\
\hline & Civil servant & $25(20.5)$ & $28(24.3)$ \\
\hline \multirow{2}{*}{$\begin{array}{l}\text { Smoking } \\
\text { status }\end{array}$} & Smoker & 78 (63.9) & $61(53)$ \\
\hline & Non-smoker & $44(36.1)$ & $54(47)$ \\
\hline \multirow{2}{*}{ Alcohol use } & Yes & $14(11.5)$ & $27(23.5)$ \\
\hline & No & $108(88.5)$ & $88(76.5)$ \\
\hline \multirow{2}{*}{$\begin{array}{l}\text { Chronic } \\
\text { disease }\end{array}$} & Yes & $36(29.5)$ & $33(28.7)$ \\
\hline & No & $86(70.5)$ & $82(71.3)$ \\
\hline
\end{tabular}

\begin{tabular}{|l|l|l|l|}
\hline \multicolumn{4}{|l|}{ Table 2. Descriptive statistics and comparison results } \\
\hline & $\begin{array}{l}\text { Patient } \\
\mathbf{n}(\text { Mean } \pm \text { SD) }\end{array}$ & $\begin{array}{l}\text { Control } \\
\mathbf{n}(\text { Mean } \pm \text { SD) }\end{array}$ & $\mathbf{p}$ \\
\hline SAAS score & $122(55.2 \pm 9.1)$ & $115(19.7 \pm 8.3)$ & 0.001 \\
\hline $\begin{array}{l}\text { HAD anxiety subscale } \\
\text { score }\end{array}$ & $122(8.7 \pm 3.8)$ & $115(7.1 \pm 2.8)$ & 0.001 \\
\hline $\begin{array}{l}\text { HAD depression } \\
\text { subscale score }\end{array}$ & $122(8.2 \pm 3.0)$ & $115(7.3 \pm 2.2)$ & 0.014 \\
\hline $\begin{array}{l}\text { SAAS: Social appearance anxiety scale, HAD: Hospital anxiety depression scale, } \\
\text { SD: Standard deviation }\end{array}$ \\
\hline
\end{tabular}


relationship $(p<0.01)$. In other words, when the SAAS scores of the individuals in the patient group increased, the HAD anxiety scores also increased (Table 3).

The correlation coefficient between the SAAS scores and the HAD depression subscale scores was 0.499 (49.9\%) which indicated the presence of a statistically significant relationship $(p<0.01)$. In other words, when the SAAS scores of the individuals in the patient group increased, the HAD depression scores also increased.

The correlation coefficient between the SAAS score and the DLQI have 0.409 (40.9\%) which indicated the presence of a statistically significant relationship $(p<0.01)$. In other words, as the SAAS scores in the patient group increased, DLQI values also increased (Table 3).

The correlation coefficient between the SAAS and the Visual Analogue Scale (VAS) was 0.605 (60.5\%), which indicated the presence of a statistically significant relationship $(p<0.01)$. In other words, when the SAAS values of the individuals in the patient group increased, the

\begin{tabular}{|c|c|c|c|c|c|c|}
\hline & & SAAS & $\begin{array}{l}\text { HAD } \\
\text { ank }\end{array}$ & $\begin{array}{l}\text { HAD } \\
\text { dep }\end{array}$ & DLQI & VAS \\
\hline SAAS scores & $\begin{array}{l}\text { Pearson } \\
\text { korelasyon } \\
\text { p value }\end{array}$ & 1 & - & - & - & - \\
\hline $\begin{array}{l}\text { HAD anxiety } \\
\text { subscale }\end{array}$ & $\begin{array}{l}\text { Pearson } \\
\text { korelasyon } \\
\text { p value }\end{array}$ & $\begin{array}{l}0.75 \\
0.01\end{array}$ & 1 & - & - & - \\
\hline $\begin{array}{l}\text { HAD } \\
\text { depression } \\
\text { subscale }\end{array}$ & $\begin{array}{l}\text { Pearson } \\
\text { korelasyon } \\
\text { p value }\end{array}$ & $\begin{array}{l}0.49 \\
0.01\end{array}$ & $\begin{array}{l}0.77 \\
0.01\end{array}$ & 1 & - & - \\
\hline VAS & $\begin{array}{l}\text { Pearson } \\
\text { korelasyon } \\
\text { p value }\end{array}$ & 0.6 & 0.77 & 0.57 & 0.88 & 1 \\
\hline
\end{tabular}

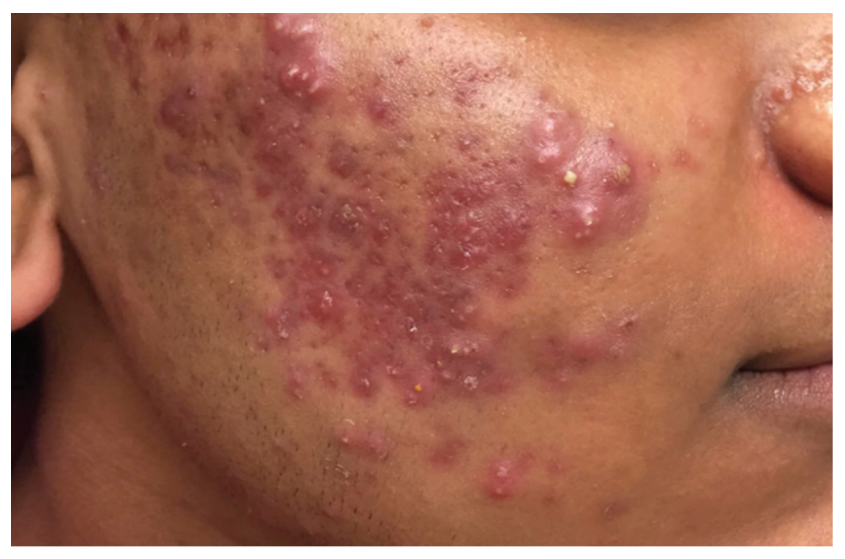

Figure 1. Patient with papules and pustules with nodulo-cystic structures in both malar areas (nodulocystic acne). The picture was shared with the permission of the patient.
VAS values also increased (Figure 1) (Table 3). Correlation in the control group was indicated in Table 4.

\begin{tabular}{|c|c|c|c|c|}
\hline & & SAAS & HAD ank & HAD dep \\
\hline SAAS scores & $\begin{array}{l}\text { Pearson } \\
\text { korelasyon } \\
\text { p value }\end{array}$ & 1 & - & - \\
\hline $\begin{array}{l}\text { HAD anxiety } \\
\text { subscale }\end{array}$ & $\begin{array}{l}\text { Pearson } \\
\text { korelasyon } \\
\text { p value }\end{array}$ & $\begin{array}{l}-0.025 \\
0.790\end{array}$ & 1 & - \\
\hline $\begin{array}{l}\text { HAD depression } \\
\text { subscale }\end{array}$ & $\begin{array}{l}\text { Pearson } \\
\text { korelasyon } \\
\text { p value }\end{array}$ & $\begin{array}{l}-0.002 \\
0.980\end{array}$ & $\begin{array}{l}0.505 \\
0.000\end{array}$ & 1 \\
\hline
\end{tabular}

\section{Discussion}

In our present study, first of all, the patient group and the healthy control group were compared. The anxiety level of the group with acne stemming from social appearances was higher than that of healthy individuals. We found that the lesions of the patients on visible areas such as forehead, cheeks and chin significantly increased the anxiety rates.

Many dermatological illnesses can cause psychological morbidity besides physical findings. While there are many works on psychiatric morbidity in dermatology patients, the anxiety levels of acne vulgaris patients stemming from their social appearance have not been emphasized yet.

The appearance of the skin is extremely important for the individual's self-image and social interaction (11). Acne can cause psychosocial burden as well as physical deterioration (12). It has been stated that patients with moderate and severe acne have impaired body image perception, create low self-perception and avoid social activities that require performance (13).

In previous studies, it was found that acne was associated with social isolation, shyness, decreased self-esteem, suicidal thoughts, anxiety and depression, and these symptoms were observed to decrease and disappear as a result of treatments for acne (3). In one study participants' social appearance anxiety, perceived acne severity and acne's impacts on their lives were inversely proportional to their quality of life. However, the perceived acne severity and acne's impacts on their lives were directly proportional to their SAA (14). While some studies show that the presence of acne aggravates anxiety, some others have not found any correlation (15).

In our study, when the patient and control groups were compared, it was found that the patients' predisposition to anxiety and depression increased. In a meta-analytical 
review evaluating 42 studies investigating the relationship between acne vulgaris and depression and anxiety, it has reported that acne had a strong relationship with psychiatric symptoms (16). This evaluation supports the results we found in our study.

Fifty-five percent of acne cases reported a close chronological relationship among emotional stress attacks and exacerbation of acne. In a larger study, the researchers stated that the cause of acne was stress in $50 \%$ of adult female acne patients $(17,18)$. A small-scale study involving adult patients found that during stressful periods, acne may worsen in these patients. In addition, changes in acne intensity are highly associated with increased stress, proposing that emotional stress from outside sources can have an important effect on acne (19).

In some reviews, it has been stated that the skin and nervous system originate from a common embryological origin, that is ectoderm, and therefore the idea that the two systems are in close relationship and similar hormones and neuropeptides are involved in both systems has been suggested $(20,21)$. Therefore, dysfunction in one of these two systems with the same origin is expected to affect the other $(21,22)$. The fact that $33.4 \%$ of patients with dermatological diseases have a concomitant psychiatric disorder explains this situation (23).

Since it has been hypothesized that the skin shares some similar property with the central nervous system stress reaction, and the hypothalamic-pituitary-adrenal (HPA) axis, more data on the causal link among emotional stress and acne can come from in vitro laboratory studies (23). If the skin has a HPA- equivalent pathway, it may be easier to understand the impact of psychological stress on certain skin conditions, including acne vulgaris (24).

In individuals diagnosed with acne vulgaris, some behavioral strategies are developed, such as avoiding being the center of attention in the opposite sex or in social environments, and avoiding eye contact, especially if tacne lesions are located on areas that may affect the body image of the person, such as the hands and face (25). In a recent study, 543 patients with perioral dermatitis, acne, folliculitis and rosacea in the facial area were compared with 497 healthy volunteers in terms of psychiatric symptoms such as anxiety and depression. Among the compared facial dermatoses, the highest anxiety and depression scores were found in acne patients (26).

Many studies have shown that acne has a negative effect on quality of life $(7,27,28)$. It has been reported that the presence of psychiatric symptoms is a strong determinant of impairment in quality of life in various dermatological diseases $(29,30)$. The patient's self-perception triggers some psychological symptoms and may determine clinical features. The VAS scale used in our study is a method by which the patient subjectively measures the severity of acne. In our study, it was found that the VAS values of the patients increased in parallel with their SAAS scores. In our study, it was also found that the SAAS scores which reflect the anxiety stemming from the social appearance of the patients, increase in correlation with the DLQI, HAD depression and HAD anxiety values.

\section{Study Limitations}

Since the SAAS and the HAD are self-report scales, subjective values will be obtained depending on the capacity of the participants and their education level. Furthermore, due to the insufficient number of patients in the patient group, the patients could not be classified according to the severity of the disease. Since our study is a cross-sectional study, it is difficult to make general inferences. The findings of the study are valid only for the university students where the study was conducted, the results may be different for individuals with different education levels and different ages. Larger studies are needed to figure out the relationship between SAA and acne vulgaris. However, the study was thought to be valuable in terms of revealing the relationships between acne vulgaris, social appearance anxiety.

\section{Conclusion}

Acne vulgaris should be considered as a disease that can affect mental health because it causes anxiety disorder caused by the social appearance of the patients. While treating patients for acne vulgaris, psychologica support should also be provided. Although acne is not associated with serious morbidity and mortality or physical disability, it may have significant psychological and social consequences. To reduce the psychosocial impact of acne vulgaris, psychological screening as well as acne treatment can be considered as a necessity. With a good acne treatment, reducing the anxiety levels of the patients due to their social appearance and strengthening their selfperception can increase the quality of life of these patients.

\section{Authorship Contributions}

Concept: F.K., Design: F.K., Data Collection or Processing: K.T., Analysis or Interpretation: G.O.Y, Literature Search: F.K., Writing: F.K., K.T.

Conflict of Interest: No conflict of interest was declared by the authors.

Financial Disclosure: The authors declared that this study received no financial support.

\section{References}

1. Golchai J, Khani SH, Heidarzadeh A, Eshkevari SS, Alizade N, Eftekhari $\mathrm{H}$. Comparison of anxiety and depression in patients with acne vulgaris and healthy individuals. Indian J Dermatol 2010;55:352-4. 
2. Cong TX, Hao D, Wen $X$, Li XH, He G, Jiang X. From pathogenesis of acne vulgaris to anti-acne agents. Arch Dermatol Res 2019;311:337-49.

3. Yolaç Yarpuz A, Demirci Saadet E, Erdi Sanli H, Devrimci Ozgüven $\mathrm{H}$. Akne vulgaris hastalarinda sosyal kaygi düzeyi ve bunun klinik değişkenler ile ilişkisi [Social anxiety level in acne vulgaris patients and its relationship to clinical variables]. Turk Psikiyatri Derg 2008;19:29-37.

4. Lukaviciute L, Navickas P, Navickas A, Grigaitiene J, Ganceviciene R, Zouboulis CC. Quality of life, anxiety prevalence, depression symptomatology and suicidal ideation among acne patients in Lithuania. J Eur Acad Dermatol Venereol 2017;31:19006.

5. Rasmussen JE, Smith SB. Patient concepts and misconceptions about acne. Arch Dermatol 1983;119:570-2.

6. Timms RM. Moderate acne as a potential barrier to social relationships:myth or reality? Psychol Health Med 2013;18:310-20.

7. Okwara BU, Ofili AN, Effiong EF, Ekhator U. Prevalence and psychosocial effects of acne vulgaris among secondary school students. Sahel Medical Journal 2021;24:34-42.

8. Doğan T. Adaptation of Social Appearance Anxiety Scale (SAAS) to Turkish validity and reliability study. Hacettepe University Journal of Education 2010;39:151-9.

9. Aydemir O. Validity and reliability of the Turkish version of the hospital anxiety and depression scale. Turkish Psychiatry Journal 1997;8:187-280.

10. Lewis-Jones MS, Finlay AY. The Children's Dermatology Life Quality Index (CDLQI):initial validation and practical use. $\mathrm{Br}$ J Dermatol 1995;132:942-9.

11. Bowe WP, Leyden JJ, Crerand CE, Sarwer DB, Margolis DJ. Body dysmorphic disorder symptoms among patients with acne vulgaris. J Am Acad Dermatol 2007;57:222-30.

12. Koo J. The psychosocial impact of acne:patients' perceptions. J Am Acad Dermatol 1995;32:26-30.

13. Fried RG, Wechsler A. Psychological problems in the acne patient. Dermatol Ther 2006;19:237-40.

14. Duru P, Örsal Ö. The effect of acne on quality of life, social appearance anxiety, and use of conventional, complementary, and alternative treatments. Complement Ther Med 2021;56:102614.

15. Niemeier V, Kupfer J, Demmelbauer-Ebner M, Stangier U, Effendy I, Gieler U. Coping with acne vulgaris. Evaluation of the chronic skin disorder questionnaire in patients with acne. Dermatology 1998;196:108-15.

16. Samuels DV, Rosenthal R, Lin R, Chaudhari S, Natsuaki MN. Acne vulgaris and risk of depression and anxiety:A metaanalytic review. J Am Acad Dermatol 2020;83:532-41.
17. Picardi A, Abeni D. Stressful life events and skin diseases:disentangling evidence from myth. Psychother Psychosom 2001;70:118-36.

18. Poli F, Dreno B, Verschoore M. An epidemiological study of acne in female adults:results of a survey conducted in France. J Eur Acad Dermatol Venereol 2001;15:541-5.

19. Chiu A, Chon SY, Kimball AB. The response of skin disease to stress:changes in the severity of acne vulgaris as affected by examination stress. Arch Dermatol 2003;139:897-900.

20. Folks DG, Warnock JK. Psychocutaneous disorders. Curr Psychiatry Rep 2001;3:219-25.

21. Cengiz GF, Gürel G. Difficulties in emotion regulation and quality of life in patients with acne. Qual Life Res 2020;29:4318.

22. Aktan S, Ozmen E, Sanli B. Psychiatric disorders in patients attending a dermatology outpatient clinic. Dermatology 1998;197:230-4.

23. Slominski A, Wortsman J. Neuroendocrinology of the skin. Endocr Rev 2000;21:457-87.

24. Slominski A, Wortsman J, Luger T, Paus R, Solomon S. Corticotropin releasing hormone and proopiomelanocortin involvement in the cutaneous response to stress. Physiol ReV 2000;80:979-1020.

25. Hodson KJ, McManus FV, Clark DM, Doll H. Can Clark and Well's (1995) Cognitive model of social phobia be applied to young people? Behavioural and Cognitive Psychotherapy 2008;36:449-61.

26. Lukaviciute L, Ganceviciene R, Navickas P, Navickas A, Grigaitiene J, Zouboulis CC. Anxiety, Depression, and Suicidal Ideation amongst Patients with Facial Dermatoses (Acne, Rosacea, Perioral Dermatitis, and Folliculitis) in Lithuania. Dermatology 2020;236:314-22.

27. Lasek RJ, Chren MM. Acne vulgaris and the quality of life of adult dermatology patients. Arch Dermatol 1998;134:454-8.

28. Kent G, al-Abadie M. Factors affecting responses on Dermatology Life Quality Index items among vitiligo sufferers. Clin Exp Dermatol 1996;21:330-3.

29. Wittkowski A, Richards $H L$, Griffiths CE, Main CJ. The impact of psychological and clinical factors on quality of life in individuals with atopic dermatitis. J Psychosom Res 2004; $57: 195-200$.

30. Sampogna F, Raskovic D, Guerra L, et al. Identification of categories at risk for high quality of life impairment in patients with vitiligo. Br J Dermatol 2008;159:351-9. 